Tube A.

\begin{tabular}{|c|c|c|c|c|c|}
\hline Fluid Used. & $\begin{array}{c}\text { Diameter } \\
\text { of } \\
\text { Tube. }\end{array}$ & $\begin{array}{c}\text { Length } \\
\text { of } \\
\text { Tube. }\end{array}$ & $\begin{array}{c}\text { Tempera- } \\
\text { ture. }\end{array}$ & Pressure. & $\begin{array}{l}\text { Time of Flow } \\
\text { of } 100 \text { Cubic Cents } \\
\text { in Seconds. }\end{array}$ \\
\hline Water, & $\begin{array}{l}\mathrm{mm} \\
\cdot 928\end{array}$ & $\operatorname{mm}_{914}$ & $17^{\circ} \mathrm{C}$ & $\underset{601 \cdot 97}{\mathrm{~mm}}$ & $69 \cdot 2$ \\
\hline Urine, Sp. Gr. 1018 & ", & , & $17 \cdot 5$ & , & $71 \cdot 3$ \\
\hline Urine, Sp. Gr. 1007 & , & " & , & , & $70 \cdot 3$ \\
\hline Cow's Milk, & , & , & $24 \cdot 6$ & $594 \cdot 3$ & $90 \cdot 3$ \\
\hline
\end{tabular}

Tube C.

\begin{tabular}{|rc|c|c|c|c|c|}
\hline Fluid Used. & $\begin{array}{c}\text { Diameter } \\
\text { of } \\
\text { Tube. }\end{array}$ & $\begin{array}{c}\text { Length } \\
\text { of } \\
\text { Tube. }\end{array}$ & $\begin{array}{c}\text { Tempera- } \\
\text { ture. }\end{array}$ & Pressure. & $\begin{array}{c}\text { Rate of Flow } \\
\text { of } \begin{array}{c}100 \text { Cubic Cents } \\
\text { in Seconds. }\end{array}\end{array}$ \\
\hline Water, . . & $1 \cdot .59$ & 914 & 15 & $601 \cdot 97$ & $42 \cdot 1$ \\
Cow's Milk, &, &,, & 27 &,, & $38 \cdot 1$ \\
Goat's Milk, &, &,, & 22 &,, & 36.09 \\
\hline
\end{tabular}

8. On Cystine $\left(\mathrm{C}_{3} \mathrm{H}_{7} \mathrm{NO}_{2} \mathrm{~S}\right)$. By James Dewar, F.R.S.E., Lecturer on Chemistry, Veterinary College, Edinburgh; and Arthur Gamgee, M.D., F.R.S.E., Lecturer on Physiology, at Surgeon's Hall, Edinburgh.

\title{
Preliminary Notice.
}

With the exception of the physical characters of this rare chemical substance, which is only known as an abnormal constituent of the human body, we know so very little, that even a few facts with regard to its behaviour with reagents may not be altogether uninteresting.

Cystine has the composition $\mathrm{C}_{3} \mathrm{H}_{i} \mathrm{NO}_{2} \mathrm{~S}$; and crystallises in the form of six-sided plates. It forms with hydrocbloric, nitric, and phosphoric acids, definite crystalline compounds.

Some of the most important facts with regard to the chemical reactions of cystine have been recorded by Dr Bence Jones, who for the first time showed that nitrous acid decomposes it with the evolution of nitrogen, and that in this operation the sulphur which it contained is oxidised to :ulphuric acid, whilst a non crystalline 
substance is left which is precipitable by nitrate of silver, mercuric chloride, as well as by acetate of lead.

The cystine used in our experiments was obtained from two portions of calculi, one of which was furnished to us by Professor Maclagan, the other by the Royal College of Surgeons of Edinburgh. The cystine was obtained by treating the pounded calculi with strong liquor ammonix, which dissolved the greater part, and allowing the solution to evaporate at a very gentle heat. The cystine which separated was then again dissolved in ammonia and recrystallised.

\section{Preparation of Hydrochlorate of Cystine.}

One gramme of cystine was dissolved in boiling hydrochloric acid; on cooling beautiful needle-shaped crystals separated, which were very soluble in water. When thoroughly dried in vacuo over quicklime the crystals were found not to be readily soluble in water. $0 \cdot 05$ grm. of crystalline hydrochlorate of cystine yielded $0.0452 \mathrm{grm}$. of $\mathrm{AgCl}$, corresponding to $22 \cdot 2$ per cent. of $\mathrm{HCl}$ (Calcd. 22.5).

\section{Action of Nitrate of Silver on Cystine.}

Cystine was dissolved in strong solution of ammonia, and to the solution was added a solution of silver nitrate in ammonia. No precipitate occurred, nor did the solution darken in the cold. When slightly acidified with nitric acid, a canary-yellow precipitate was thrown down, which was collected and dried in vacuo. The filtrate blackened when heated, and on filtering off the black precipitate a clear colourless solution was obtained, which was not further blackened when boiled with ammoniacal solution of oxide of silver.

On analysis the substance precipitated proved to be a compound of cystine with nitrate of silver.

In a subsequent experiment an ammoniacal solution of cystine was boiled with an ammoniacal solution of nitrate of silver. A black precipitate fell which consisted of sulphide of silver. The filtrate from the precipitate of sulphide of silver was subsequently treated with solution of chloride of ammonium to separate the excess of silver. The solution was found not to be precipitated by hydrochloric acid and chloride of barium, nor by sulphate of cal- 
cium. It is therefore evident that when an ammoniacal solution of cystine is heated with ammoniacal solution of oxide of silver, the sulphur is separated entirely as sulphide of silver, none being oxidised; it is also obvious that no oxalic acid is formed.

Action of Caustic Soda and Caustic Baryta on Cystine.

Cystine, when treated with pure solution of pure $\mathrm{NaHO}$, and evaporated in a silver basin, gives a reddish fluid; sulphide of sodium is then produced, blackening the basin, and ammonia is copiously evolved. On treating the residue with water, neither sulphuric nor oxalic acids can be detected. The liquid contains, however, a large quantity of sulphide of sodium with a mere trace of sulphite.

Cystine, when heated to $150^{\circ} \mathrm{C}$. with solution of caustic baryta in sealed tubes, gave off ammonia, a large quantity of sulphide of barium, a smaller quantity of sulpbite of barium, and a trace of hyposulphite being formed. No trace of sulphocyanide could be detected.

Action of Alcoholic Solution of Potash on Cystine.

Cystine was heated for several hours in a sealed tube at $130^{\circ}$ with an alcoholic solution of potash. At the conclusion of the experiment a small quantity of dark sticky matter was found adhering to the tube, which contained a yellowish fluid. The latter smelt strongly of ammonia, which was separated by distillation. The residue was acidified with dilute sulphuric acid, and shaken up with ether. Ether left a yellow non-crystalline substance, possessed of an indefinite but disagreeable odour. This substance had a strong acid reaction, and was found to contain no sulphur.

\section{Action of Nascent Hydrogen on Cystine.}

When cystine is added to a mixture of tin or zinc and dilute hydrochloric acid, large quantities of sulphurated hydrogen are given off ; the evolution of gas gradually slackens, till even after the action has gone on for several days, traces of sulphuretted hydrogen continue to be given off. When treated in the same manner taurine does not evolve $\mathrm{H}_{2} \mathrm{~S}$.

It is to be noted that this evolution of $\mathrm{H}_{2} \mathrm{~S}$, when cystiue is 
treated with tin or zinc and hydrochloric acid, might be used as a test for the substance, care being previously taken to separate any sulphide which might exist.

\section{Action of Nitrous Acid on Cystine.}

Cystine was placed in water and a strearn of nitrous acid gas passed through it. No action took place until the water was heated; it then commenced and proceeded briskly, with abundant effervescence, until the whole of the substance was dissolved.

The clear solution contained a large quantity of sulphuric acid, but not a trace of oxalic acid. When boiled with an ammoniacal solution of nitrate of silver, considerable reduction took place, a beautiful mirror of silver being deposited on the glass. The fluid was again subjected to the action of nitrous acid; still no oxalic acid could be found, and the reduction of an ammoniacal solution of oxide of silver continued. A portion of the fluid was treated with carbonate of barium and heated; the clear filtrate had an alkaline reaction, and was abundantly precipitated by nitrate of silver and acetate of lead. The remainder of the fluid, after the treatment with $\mathrm{BaCO}_{3}$, was treated with solution of nitrate of silver. An abundant canary-yellow precipitate was formed. This was suspended in water and decomposed with $\mathrm{H}_{2} \mathrm{~S}$; the filtrate was evaporated to dryness, and presented the appearance of a sticky solid. It was soluble in water. The aqueous solution was evaporated and treated with absolute ether, which dissolved the greater part. The ethereal solution left on evaporation an acid fluid. This was dissolved in water, neutralised with ammonia, and precipitated with solution of nitrate of silver. The yellow precipitate obtained was amorphous; it was dried in vacuo. Two specimens of the silver salt prepared at different times were analysed by us. The following are the results of two analyses:-

$\begin{array}{lllll}\text { Silver, . } & . & . & 56.9 & 57.5 \\ \text { Carbon, . } & . & . & 19.43 & 21.32 \\ \text { Hydrogen, } & . & . & 5.29 & 4.64\end{array}$

In considering the discrepancies of these analyses, it must be borne in mind that we were operating in excessively small quantities of a substance prepared at different times by complicated processes. 


\section{Remarks.}

Cramer believed that cystine was intimately related to the body called Serin, $\mathrm{C}_{3} \mathrm{H}_{7} \mathrm{NO}_{3}$, which is obtained as one of the products of the action of alkalies on silk. Serin, when treated with nitrous acid, yields glyceric acid, as alanine under the same circumstances yields lactic acid, and therefore serin may be looked upon as amido-glyceric acid.

Cramer further believed that cystine was a sulpho-amido-glyceric acid, i.e., serin in which hydroxyl has been replaced by HS.

This supposed relation is exhibited below-

$\begin{array}{lll}\mathrm{CH}_{2} \mathrm{OH} & \mathrm{CH}_{2} \mathrm{NH}_{2} & \mathrm{CH}_{2} \mathrm{NH}_{2} \\ \mathrm{CHOH} & \mathrm{CHOH} & \mathrm{CHSH} \\ \mathrm{CO}_{2} \mathrm{H} & \mathrm{CO}_{2} \mathrm{H} & \mathrm{CO}_{2} \mathrm{H} \\ \text { Glyceric Acid. } & \begin{array}{c}\text { Amido-glyceric Acid } \\ \text { or Serin. }\end{array} & \text { Cystine. }\end{array}$

Considering that this relation of cystine to serin really exists, some have argued that on treatment with nitrous acid, cystine should yield glyceric acid. We do not, however, admit that this would really be the case. If we examine the case of sulpho-lactic acid, an analogous body to the supposed sulphur derivative of serin, we find that, on oxidation, it gives sulpho-propionic acid, and therefore we should, in the case of cystine, expect that a sulpho-acid would be formed on treatment with nitrous acid, were it built up as Cramer supposed. We have uniformly observed, during the course of our experiments, that, however carefully we attempted to regulate the action of nitrous acid on cystine, or of a nitrite on a salt of cystine, the sulphur separated as sulphuric acid thus pointing to a material difference in its reactions from what we should have expected from its supposed constitution. Although we cannot consider our experiments as definitive, we can assert that glyceric acid is not a product of the action of nitrous acid, and we venture to predict that, in all probability, cystine will be found to be related to pyruvic acid-to be an amido-sulpho-pyruvic acid. We base this supposition on the near approach of the analyses of the silver salt of the acid obtained by the action of nitrous acid on cystine, to the composition of a pyruvate, and on the general character of the oily acid produced.

We intend to pursue this subject further.

voL. vII. 